Research Report No. 48/2013

\title{
Giving and Taking Offence: Civility, Respect, and Academic Freedom
}

Jamie Cameron

Osgoode Hall Law School of York University, jcameron@osgoode.yorku.ca

Follow this and additional works at: http://digitalcommons.osgoode.yorku.ca/clpe

\section{Recommended Citation}

Cameron, Jamie, "Giving and Taking Offence: Civility, Respect, and Academic Freedom" (2013). Comparative Research in Law \& Political Economy. Research Paper No. 48/2013.

http://digitalcommons.osgoode.yorku.ca/clpe/290 


\section{OSGOODE}

OSGOODE HALL LAW SCHOOL

YOR K UNIVERSITY

\section{OSGOODE HALL LAW SCHOOL}

Comparative Research in Law \& Political Economy

RESEARCH PAPER SERIES

Research Paper No. 48/2013

Giving and Taking Offence: Civility, Respect, and Academic Freedom

Jamie Cameron

Editors:

Peer Zumbansen (Osgoode Hall Law School, Toronto, Director Comparative Research in Law and Political Economy)

John W. Cioffi (University of California at Riverside)

Comparative Research in Law \& Political Economy 


\title{
15 \\ GIVING AND TAKING OFFENCE: CIVILITY, RESPECT, AND ACADEMIC FREEDOM
}

\author{
Jamie Cameron
}

\section{INCIVILITY'S RISE}

Few choose to be offended, and it is little surprise that the instincts react quickly and protectively, demanding that transgressors be stopped or punished and shared values restored. The law in Canada addresses high-level offensive expression by prohibiting hate speech under the Criminal Code and regulating discrimination through human rights provisions. Measures that restrict expressive freedom in the name of equality mean that tolerance for offensiveness can be low where comments target visible minorities or disadvantaged groups that are protected by the law. By way of example, a recent human rights decision concerned an open mike comedy show at a restaurant one evening, which assumed an ugly tone when the host called out and insulted lesbian customers. In proceedings arising from the incident he argued, to no avail, that unscripted comedy shows are notoriously tasteless, and often trade on stereotype for humour. Any suggestion that the audience or targets of his remarks would or should not take the material at face value was quickly dismissed. ${ }^{1}$

Hate speech and human rights provisions place well established, though controversial, limits on expressive freedom. A more recent phenomenon is the civility juggernaut, a movement that has gained momentum in response to the perception that uncivil conduct has 
reached epidemic proportions. ${ }^{2}$ There is now a healthy literature, both popular and academic, on the phenomenon and on what steps must be taken to reverse the so-called "culture of incivility." 3 If it hardly counts as a new discovery, the meteoric rise and escalation of incivility is much ballyhooed just the same. Whatever can or cannot be proved, it is widely assumed and believed that incivility endemically infects current government, business, media and social media processes. ${ }^{4}$ It is all around and must be curbed.

Corrections are becoming increasingly commonplace across the spectrum. Early in 2013, behaviour in the House of Commons became so dysfunctional that Nathan Cullen decided to launch an initiative he termed the "Civility Project." 5 Partisan exchanges in the House may be uncivil by definition, and it is unclear in any case how serious Cullen was about implementing the proposal. Under his plan, incivility in Parliament would be monitored by empowering the Speaker to suspend offenders without pay and withhold their privileges in Question Period. After being discussed and even ridiculed for a time, Cullen's Civility Project fell away and has not been heard from in months. ${ }^{6}$

Otherwise, civility standards are taken seriously in the legal profession, where law societies have the power to discipline lawyers for breaches of ethical and professional standards, including incivility. To date the decision maker's authority to decide which words, gestures and actions are polite enough to satisfy a lawyerly standard of courtesy has not been especially controversial. ${ }^{7}$ One critic who questions civility enforcement in the legal profession points out that a focus on manners, and vocabulafy, it particular, is misplaced because it can deflect attention from the serious ethical issues at stake. ${ }^{8}$

Meanwhile, the status of expressive freedom at universities is a perennial debating point, with some taking the view that there should be freer rein on campus, and others claiming that restrictions are necessary to support a safe environment for learning and the pursuit of knowledge. If the principle of academic freedom points up what is distinctively at stake when speech activities on campus are restricted, hate speech laws, human rights codes and other limits on expression, such as the law of defamation, apply here, as elsewhere. Despite academic 
freedom, there is much to suggest that tolerance for language and remarks perceived to be offensive may be just as low at universities. ${ }^{9}$

Far from being insulated from it, universities are in the vanguard of the current civility movement, and institutions of higher learning have eagerly taken up the cause. By now, any variety of well-intentioned policies aimed at bringing civility to, or restoring it on, campus have been introduced. Though they place significant limits on expressive freedom and engage the principle of academic freedom at its core, the implications of these policies have not been fully explored. This short paper fills that gap by explaining how policies that institutionalize a standard of civility - or courtesy - threaten the freedoms that anchor the university mission. In doing so, the discussion draws insights from the traditions of academic and expressive freedom to show why it is imperative that expressive freedom be protected to its maximum in university settings. In particular, the analysis leverages the Charter of Rights and Freedoms and its guarantee of expressive freedom to reinforce academic freedom and broaden the scope of protection for freedom on campus. ${ }^{10}$ It concludes that civility is an aspiration that is better served by collaborative, rather than regulatory, measures, and maintains that restrictions on speech activities must be limited to instances of more transgressive conduct, such as harassment and bullying.

\section{CIVILITY, RESPECT AND THE UNIVERSITY}

Restrictions on free inquiry and debate at universities have taken many forms over the years. It was not so long ago that controversy swirled around the "campus codes" which took aim at racist, sexist and other discriminatory messages that target identifiable communities. ${ }^{11}$ As ongoing debates about these and other forms of hate speech show, restrictions are problematic in any setting because the line between what is merely offensive and what is harmful enough to prohibit and punish is hard to draw. Definitions are a particular concern because vague and overbroad regulations place expressive freedom in danger and create a risk of censorship. In the university context, there is a further dynamic at work, and that is the principle of academic freedom. Though it also has a broader and more inclusive meaning, it 


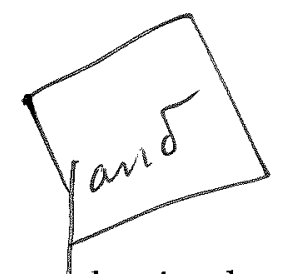

$\sqrt{\text { is accepted by most achdemics that academic freedom is a professional }}$ $\checkmark$ entitlement of faculty, not a right that belongs to other or all members of the community, such as students. ${ }^{12}$ On that view, academic freedom $\checkmark$ has a distinctive function and cannot be zesponsibte for defending free $\checkmark$ speech in the myriad ways it is challenged on campus. 13 Academic and $\checkmark$ expressive freedom serve and protect different purposes, the two overlap and share an interest in civility standards and their negative consequences for freedom on campus.

In recent years, universities have begun to supplement existing regulations on highly offensive speech with policies on civility and a respectful workplace. As any number of online resources attest, institutions of higher learning across North America have embraced the civility cause in earnest. One example is the University of Missouri's "Show Me Respect" project, which serves as an umbrella for a concept of civility, broadly understood, and includes materials on bullying as well as a "civility toolbox." 14 Another is the University of Wisconsin Oshkosh, which in 2011 hosted a well-publicized forum titled "Civility in Everyday Life." 15 The temper of the times is reflected in the forum's stated premise that "we demonstrate civility when we show respect for others, especially those with beliefs, lifestyles and political beliefs that are different from our own," and aspiration of engaging campuses in "critical civility conversations and best practices that will serve as catalysts for campus climate change." 16

If initiatives that rest on a conception of incivility as "the quality of being uncivil" lack content and parameters, the movement has not been deterred by that and has proceeded to set, promote, and enforce campus standards of courtesy. Some incorporate, and overlap with, pre-existing and separate policies on discrimination, harassment, and bullying, though more generally their purpose is to monitor the content, manner and tone of relationships and engagement on campus. It is critical to understand that, unlike regulations that focus on more extreme expressive activity and set defined limits on speech, civility and respectful workplace standards extend the concept of what is offensive in significant ways. These standards speak not only to the content but also to the manner of discourse, debate and exchange.

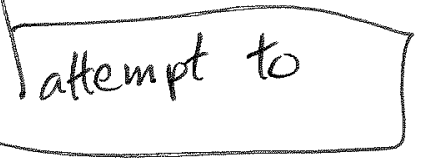


Whatever can or might offend is potentially within the purview of these policies.

Though it is a White Paper, not university policy, the University of Maryland's 2013 report, "The Civility Discourse," provides colour on the direction and tone of today's civility projects. ${ }^{17}$ Having accepted that "[d] espite scholars' attempts to offer a simple comprehensive definition, civility is an expansive term open to subjective interpretation,"18 the report note that civility has been defined as "civilized conduct; especially: courtesy, politeness', or simply 'a polite act or expression, ${ }^{\prime \prime}$ ant then adopted "niceness to others" as its working definition. As explained, this definition was chosen because niceness "may easily be understood by all parties affected."19 The report to describs it as nebulous, and endorse a definition of incivility as "low intensity deviant behavior with ambiguous intent to harm the target, in violation of university norms for mutual respect'."20 Under these definitions, it is not surprising that uncivil encounters can occur between students and faculty, faculty and staff, and staff and students. That said, the White Paper declare that because the behaviour trickles from the top down, "it is important to stamp out uncivil behavior within the highest ranks while training those in subordinate roles how to handle incivility from leaders." 21 According to the report, there good support on campus for "a zero-tolerance approach to incivility," with every individual, including campus leaders, being held accountable and a system in place to provide a remedy to aggrieved parties and a means of enforcement for administration. ${ }^{22}$

With less fanfare, Canadian universities have responded with their own protocols, which run the spectrum from conduct that is directly harmful or threatening, to expressive activity that may insult, marginalize or upset another person. Two examples are the University of Toronto's "Human Resources Guideline on Civil Conduct"23 and Ryerson University's "Guide to Civility" and "Workplace Civility and Respect Policy." 24 Because they juxtapose civility and incivility and establish an institutional standard of courtesy, both can be considered fairly representative. ${ }^{25}$

The Toronto Guideline describes civil conduct, variously, as "treat- 
ing others with dignity, courtesy, respect, politeness, and consideration," "speaking in tones of voice that are appropriate for the circumstances," and "managing conflict with others in a respectful way rather than a confrontational way." 26 Meanwhile, Ryerson's Workplace Civility and Respect Policy less expansively states simply that "[c]ivility involves treating others with dignity and respect and acting with regard to other's feelings," and requires that "even the most critical feedback be delivered respectfully, privately and courteously." 27

As for its opposite, the Toronto Guideline defines uncivil conduct, among other things, as "humiliating, degrading, demeaning, belittling, insulting, frightening or intimidating another person," "distributing comments about an individual that are unjustified and likely to have a negative impact on the individual," and "telling inappropriate jokes." 28 Ryerson's checklist is more extensive, and includes "unprofessional behaviour; rudeness; shouting or swearing; intimidation or bullying; threatening comments or behaviours/actions; [and] unsolicited and unwelcome comment ... gestures, actions or contact that cause offence, humiliation or physical or emotional harm." 29 In more detail, Ryerson's policy also states that uncivil behaviour includes comments or conduct a person knows or ought to know is "unwelcome, offensive, embarrassing or hurtful," and cautions that "behaviour that is considered perfectly acceptable by some people, and in some cultures, may be considered inappropriate and rude by others." ${ }^{30}$ Uncivil behaviour is not excused, under the policy, because it is subjective or unintentional. Because it is the experience of incivility that is important, its genesis - including who the speaker is and what the context was - seems to matter little, if at all. ${ }^{31}$

The purpose of these policies is to prevent and address behaviour that is perceived as offensive because the content, tone or manner of delivery may be rude, insensitive, forceful, or thoughtless. It is accepted without hesitation that civility and respect are the hallmarks of effective and rational debate, and their value in human discourse, whether academic or non-academic, is not open to question. After all, who does not prefer civility to barbarism? ${ }^{32}$ From that perspective, it may seem quite reasonable to establish and then enforce standards for discourse. 
The problem is that regulations of this kind cannot be institutionalized without compromising academic and expressive freedom.

Definitions are a central concern. The forum on "Civility in Everyday

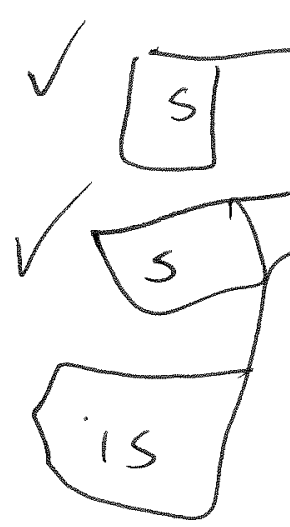
Life" frankly admited that "what constitutes civility (or incivility, for that matter) is neither well understood nor readily apparent," but suggested, optimistically, that this due to the lack of "shared opportunity to reach agreement on what constitutes civil behaviour. " 33 More alarming is the White Paper's standard of "niceness to others" which, on its face, is without limits on what civility can encompass. The utter subjectivity of these standards is also evident in muzzy concepts like "camouflaged aggression." 34 Ryerson's policy acknowledges that subjectivity, though not in a way that cautions against an overextension of the standard, but for the opposite reason of emphasizing that it is the experience of incivility - however subjective the response may be that matters. When and in what circumstances another person might take offence at things said a certain way is unpredictable and highly situational. Civility policies necessarily lend themselves to selective enforcement: though most will not, some offenders will be singled out for institutional attention; by definition and in practice, even handed application of the standard is impossible. Short of a pattern of behaviour that satisfies definitions of harassment and bullying, mere rudeness and a lack of courtesy is just too pervasive and constant to be sensibly regulated.

A second definitional issue concerns the relationship between civility and respect standards and more serious transgressions, such as harassment, bullying and discrimination. ${ }^{35}$ Specifically, conduct that is often or usually addressed in separate regulations may also be included in civility policies. This creates a synergy that is problematic, in the first instance, because associating incivility with more serious forms of harm upgrades conduct that otherwise would be notable only as a breach of courtesy.

At the same time, the scope of those more serious behaviours is also expanded when conduct that is no more than discourteous or disrespectful is drawn into the zones of harassment and bullying. At OCAD, for instance, bullying includes "discrediting a person, 
spreading rumours [or] calling into question his or her convictions"; "preventing a person from expressing himself or herself"; "no longer talking to an individual or ignoring their presence"; "destabilizing a person"; and "finger pointing." 36 It is unclear how persistent any of those behaviours must be or what impact they must have to cross the threshold from bad behaviour to bullying. Another example is Memorial University's Respectful Workplace policy, which states that "[h]arassment in any form is unacceptable," and then defines harassment as "any comment or conduct towards another person which is abusive, offensive or demeaning." 37 Porous definitions that do not establish a threshold of harm or set boundaries between levels of harm aggravate the interference with academic and expressive freedom.

The further risk under these policies is that a focus on incivility will deflect attention from content and sideline messages that might be critically important. ${ }^{38}$ Moreover, the pall or chill these policies may place on debate, discourse, and exchange is costly. In that regard, it must be remembered what academic and expressive freedom protects. These entitlements are not an apology for bad behaviour, and although they defend the free speech of individuals the more important point is that freedom is the condition that inspires human potential. To stifle or silence those who reject convention or refuse to conform to norms of civility is to risk losing that potential, including what uncivil outliers have to offer. As Justice Jackson of the US Supreme Court so famously and dramatically observed, "compulsory uniformity of opinion achieves only the unanimity of the graveyard." 39 If a among us statement made during wartime and debate about the constitutionality of compulsory flag salute is more freighted with significance than solicitude for those who choose to be rude, the point is that coercion of thought - and in this context, manner can be added - is a dead end for freedom.

Taking account of these concerns, it is open to question whether incivility, defined in the policies and proposals discussed here, is harmful enough to justify the interference with freedom and the commitment of resources that beeded to enforce standards of courtesy. On any view, policies that purport to set a standard of civility

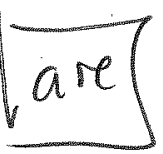


cut deeply into choices not only about what can be said but also how a message must be presented. Imposing norms of civility and respect put a bounty on the kind of open discourse that defines the university mission. Just as policies that hold faculty to a standard of courtesy and manners violate the principle of academic freedom, policies that muffle the raw energy of students' activities violate their expressive freedom.

The point is not to legitimize or excuse rudeness, incivility or offensiveness. Yet it is well known that these lapses of civility are pervasive in public spaces, including and perhaps especially the internet. Few of us can avoid offence for any sustained period, as modern life exposes us to giving or taking it in much of what we do. The answer is not to compel compliance with a standard of courtesy, not even for good reason, because the cost to freedom is too high. This is especially true at universities, which must promote a fearless spirit of inquiry, not tame it.

It is disappointing that, if they address it at all, civility and respectful workplace policies seem to assume that those it binds - faculty, students, and employees - have forfeited their rights of expressive freedom. Though most universities declare unflinching commitment to the principle, academic freedom also plays a curious role, at best, in these policies. Some do not mention it at all, and appear to have forged ahead with civility as though consideration of academic freedom is irrelevant. 40 Others make hortatory gestures to academic freedom before declaring that mandatory standards of civility and respect do nothing to subtract from or interfere with this principle. ${ }^{41}$ Finally, some also suggest that the two can be harmonized as, for instance, by stating the "simple truth" that "incivility threatens academic freedom while civility enhances, nurtures and supports it." 42

More detailed consideration of these policies, together with a deeper analysis of the relationship between academic and expressive freedom, must be left to another day. For now, this much can be said. Academic freedom is at the core of the university mission, but it cannot be fully exercised or enjoyed in the absence of expressive freedom. ${ }^{43}$ At the same time, though it is not a student entitlement, students inhabit and 
contribute dynamic force to an environment which accepts and commits to the principle of academic freedom. It follows that whether and how students exercise expressive freedom in that environment must be inflected by that principle.

With the foregoing framework in place, the law can now be brought into the analysis. The Charter of Rights and Freedoms and its guarantee of expressive freedom under s.2(b) ${ }^{44}$ should figure prominently in any analysis of expressive freedom at universities. ${ }^{45}$ The discussion which follows shows that the Charter jurisprudence can refresh, reinforce and even expand protection for academic freedom - understood both in broad terms as a descriptor of an entitlement belonging to the university community at large, and in its conventional sense as a vocational or professional entitlement of faculty. Two assumptions ground the analysis which follows. First, it is difficult to imagine expressive freedom having less status at universities than in other settings; it should have at least as much protection on campus as it does elsewhere, and not less. Second, and equally vital, the university context and principle of academic freedom inflect the Charter's concept of expressive freedom because the university plays distinctive social, public, and intellectual roles. The gravitational pull of academic freedom as the foundation of intellectual growth, discovery and creativity should mean fewer restrictions on free speech at universities. What emerges from these considerations is a model for freedom on campus that can be constructed by joining the two entitlements and allowing them to complement each other.

\section{EXPRESSIVE FREEDOM AND THE UNIVERSITY}

Recognizing that academic freedom and expressive freedom overlap, but do not serve identical purposes, is the starting point and it is important, as a result, to be clear about their interface in this paper. If academic freedom does not directly or explicitly protect expressive freedom, at the least its function and status explain why free speech must be at its apex in a university setting. At the same time, university policies draw the Charter into the discussion and show in this instance why civility and respectful workplace policies - with their open-ended 
definitions and restrictions on the content and manner of expression - infringe academic freedom and as well as expressive freedom.

An initial, technical question about the Charter is whether it applies to or binds universities. It is clear that the Charter prohibits governments from violating the rights and freedoms of Canadians, but less certain which actors and institutions are bound by it because they represent government or serve a government function. Canadian universities are for the most part public, rather than private, institutions. They may be constituted or incorporated by statute and are substantially funded, as well as regulated to some degree, by government. Those connections may indicate that the Charter should apply, though the Supreme Court found to the contrary early in its history when it wrote a landmark decision holding that mandatory retirement policies were not subject to the Charter. 46 That was some time ago and the Court's view could shift in light of subsequent developments, including a recent decision in which university students raised s.2(b) of the Charter when the university brought discipline proceedings against them for a Facebook posting. ${ }^{47}$ That said, the universities are not immune from the Charter, and its formal application is one way, but not the only way, for the s.2(b)'s guarantee to support free speech on campus. ${ }^{48}$

Whether or not the Charter applies is less critical because of a parallel branch of Supreme Court jurisprudence which addresses the broader role of Charter values in Canada's legal and political culture. Under this branch of doctrine, Charter values influence the evolution of the law and fetter the discretion of those who exercise decision making authority. A prime example is defamation - a field of private law not subject to the Charter - which has been modernized through the direct incorporation of Charter values into common law doctrine. 49 In addition, the Supreme Court has responded on a second front by requiring that decisions affecting constitutionally protected rights and freedoms comply with Charter values.

Doré $v$. Barreau du Québec is instructive on that question because it pitted expressive freedom against civility in the context of discipline proceedings that reprimanded a lawyer for sending an offensive letter to a judge. ${ }^{50}$ In the circumstances, the Supreme Court upheld the 
Barreau's 21-day suspension of the lawyer but also stated that the free speech rights of lawyers must receive strong protection. As Abella J. indicated, the importance of civility in the legal profession must be measured against the severity of the conduct and the "public benefit in ensuring the right of lawyers to express themselves about the justice system in general and judges in particular." 51 Specifically, she stated that "proper respect" for expressive freedom requires discipline bodies to tolerate a certain amount of "discordant criticism."52 In particular, she held that the decision maker had to demonstrate that expressive freedom received due regard, and noted in particular "an individual lawyer's right to expression and the public's interest in open discussion." 53

In these ways the Charter exerts influence through the concept of Charter values. What that influence is and how it should be measured raise questions that will depend on the context. To illustrate, Charter values play an important role in the law of defamation because the rules of libel have serious consequences for expressive freedom. By the same token, Doré is an illustration of the way Charter values are incorporated into the structure of administrative decision making. By analogy, Charter values should have significant influence in defining expressive freedom on campus, not only because universities are public institutions - regardless of their status under the Charter - but also because the values at stake are at least as compelling, if not more compelling, in a university setting.

Context is a central concept in the Supreme Court's s.2(b) jurisprudence and a fundamental consideration in any discussion of expressive freedom at universities. Briefly, taking account of context means that the scope of free speech on campus cannot be determined without considering academic freedom and the critical role it plays in framing the university mission. In other words, whatever freedom might require under s.2(b) must reference academic freedom and what it requires, not simply to survive, but more importantly to thrive. That, in essence, is the role context plays in Charter analysis.

The affinities between s.2(b)'s underlying values and the fundamental purposes of academic freedom are readily apparent. 54 Both 
recognize and value the freedom to explore, create and share without constraints or conditions, because the search for truth - understood in relative terms as a process for the enlargement of knowledge and experience, rather than as a pretext for privileging dogma and orthodoxy - can only prosper when that search is open, fearless and boundless. Expressive freedom is a key element of academic freedom, and faculty cannot fully exercise and enjoy their professional entitlement when the content or manner of their debates, exchanges and discourse are unjustifiably limited. In addition, students who cannot claim academic freedom in their own right are nonetheless its beneficiaries, and have their own rights of expressive freedom which must be interpreted by reference to the university setting and its commitment to learning. For these reasons, expressive freedom has a distinctive texture and urgency at universities which must be reflected in the way Charter values apply to this context. All this to say that expressive freedom applies at full force, and then some, at universities. What s.2(b) and the Charter add are concrete principles - the way to make the argument - that will maximize expressive freedom on campus for student members of the community as well as for faculty. These concrete principles, which are identified below, explain why civility and respectful workplace policies place academic freedom and expressive freedom so much at risk.

Over the last thirty years s.2(b) of the Charter has attracted considerable attention, and generated a rich body of jurisprudence at the Supreme Court of Canada. The Court has issued strong pronouncements about s.2(b) but also upheld a variety of restrictions on offensive expression, including restrictions on hate speech under the Criminal Code and in human rights legislation. ${ }^{55}$ Overall, the jurisprudence is disappointing because the Court has too readily and consistently endorsed limits on expression without proof that it causes harm, and done so on the basis that "low value" expression should receive less protection under the Charter. This approach, which assumes that constitutional protection should turn on subjective perceptions of an idea's value, unfortunately shows how unwilling or unable the Court has been to recognize what censorship is and to adopt principles that 
will prevent it from happening. 56

Although the Supreme Court's methodology is flawed, that should not obscure the fact that restrictions on offensive expression in the era of the Charter are narrow in scope and exceptional in nature. The Court confirmed that view in its 2013 decision in Saskatchewan (Human Rights Commission) $v$. Whatcott, which upheld a hate speech provision in human rights legislation but in doing so placed significant restrictions on its scope. ${ }^{57}$ In discussing civility and respectful workplace Letureen policies, it is critically important to recognize that Whatcott relied heavily on a distinction hate speech and offensive expression. Specifically, the Court compared hate speech to expression that is repugnant, offensive, humiliating or belittling, and concluded that hate speech causes harm and can be regulated for that reason, but that the others do not and are protected by the Charter. 58

More detail demonstrates just how crucial the distinction was to members of the Court. Rothstein J.'s majority opinion explained that hate speech is concerned with extreme and egregious expression, not that which is "merely offensive or hurtful." 59 Accordingly, he maintained that hate speech does not target ideas and is not aimed at discouraging "repugnant or offensive ideas," because "[a] blanket prohibition on the communication of repugnant ideas would offend the core of freedom of expression." 60 In other words, hate speech can be prohibited because of its particular and distinctively harmful effects, but other offensive expression - including the highly offensive - is not harmful enough to override s.2(b)'s guarantee of freedom. It is striking that the Court made the point forcefully in Whatcott, and repeated it several times.

In carving out a narrow area for the regulation of hate speech and granting protection to other forms of offensive expression, Whatcott reinforced first principles in the s.2(b) jurisprudence. ${ }^{61}$ Foremost is the principle of content neutrality, which was adopted early in the s.2(b)'s history, and states that the Charter protects all expressive activities indiscriminately, and without regard to content, "so as to ensure that everyone can manifest their thoughts, opinions, beliefs, indeed all expressions of the heart and mind, however unpopular, distasteful or 
contrary to the mainstream." ${ }^{62}$ Content neutrality is the indispensable condition of expressive freedom, and is based on an assumption of equal status between ideas. Under this concept of freed $m$ e expression cannot be censored, targeted, or discriminated against because of the message. As such, it embeds an equality principle for speech that is based on a presumption against censorship and content discrimination.

Section 2(b)'s core values are another vital component of the jurisprudence. Values which include truth seeking, democratic governance, and self realization are deeply entrenched in the jurisprudence. They are of primary importance because they confirm that expressive freedom must be valued in the abstract, at large, and without reference to its content. A commitment to those values recognizes that the guarantee's core is freedom - and not the content of any particular message, whether noble or ignoble. Section 2(b) must be understood at this level of abstraction for freedom to be meaningfully protected in the particular. Otherwise, the instinct to censor and suppress messages because of their offensive content or manner of delivery will easily prevail.

A third key element is the concept of proportionality, which governs the question of reasonable limits on rights and freedoms that are permitted under s.1 of the Charter. Again, an aside on the technicalities of the Charter must be added. In textual terms, the Charter's structure separates the protected rights and freedoms from the concept of reasonable limits, which allows Charter violations to be "saved" if the government can demonstrate that they are justified. ${ }^{63}$ Here, as well, the Supreme Court's jurisprudence is disappointing because it has softened the burden of justification the government must satisfy and allowed too many limits to be upheld. As noted above, it has misused s.2(b)'s abstract values against expressive freedom, to support restrictions on speech when the content is deemed to be of low value. ${ }^{64}$ Nonetheless, what matters more is the guiding principle, emphasized and reinforced by Whatcott, that narrow regulation is required where expressive freedom is at stake.

Context, content neutrality, the underlying values, and proportion- 
ality are the leading s.2(b) principles. Without applying in a mandatory, structured way, they influence the concept of Charter values and what compliance with those values will require in any given circumstances. It is clear, under these principles, that civility and respectful workplace policies place restrictions on freedom that undermine the Charter's commitment to free speech. Restricting expressive activities because their content or manner of delivery is offensive violates the principle of content neutrality. Rules that impose conventions of civility also undermine the underlying values of academic and expressive freedom, and compromise the integrity of the freedom those values are meant to protect.

Typically, these policies contemplate more pervasive and intrusive limits on expressive freedom than regulations that address hate speech, harassment, bullying, and discrimination. The problem is that defining uncivil conduct in broad and overreaching terms unavoidably offends the Charter's concept of proportionality. For these reasons, expressive activities are subject to institutional regulation because they disclose a lack of courtesy or respect fall well outside the boundaries of regulation carefully mapped by Whatcott.

To this a word about enforcement can be added. The subjectivity and selectivity of what is enforced, and against whom, is unavoidable under civility and respectful workplace policies. And although enforcement under these models can take many forms, most create a system or process for making and hearing complaints. Whether or not, and to what extent they are enforced, it should not be forgotten that, even without enforcement, these policies undermine freedom because they inhibit and chill frank discussion and candid exchange. When enforced, they pose an even greater danger to the mission of the university.

The requirements of freedom are compelling because free inquiry in the ongoing aspiration of enhancing knowledge and experience is the raison d'etre of the university. To put constraints on the content, tone and manner of discourse, exchange and communication in the name of courtesy is to place the university and its central purposes in harm's way. Short of more transgressive behaviours which cause direct harm, 
such as a pattern of harassment or bullying, expressive activity should not be regulated simply because it violates a standard of courtesy and is offensive for that reason.

\section{CIVILITY AND FREEDOM}

Rudeness in most instances is counter productive and should not be excused. The values civility and respectful workplace policies seek to enforce are important and should be supported. Yet it is a different question whether standards of behaviour should be enforced by institutional regulation.

Freedom is fragile because those who seek its protection are often or invariably the ones who are least sympathetic. Their expressive activities invite attention and oversight because they are offensive, confrontational, and even abusive: they reject the standards the rest of us observe, and that offends our sensibilities. As much as we may disapprove of the content or manner of their expression, that is not reason enough to silence or punish their interventions. Unless and until they cross a threshold of harm that justifies a regulatory response, transgressions that are merely offensive must be tolerated and addressed by other means.

Defining that threshold is a challenge that cannot be taken up in the late stages of this paper. Suffice to say that the threshold will be reached when there is a pattern of behaviour that is persistent and targeted enough to pose a risk of harm that outweighs the interest in protecting academic and expressive freedom. Whether characterized as harassment, bullying, fighting words, or hate speech, conduct that is regulated under these headings must also be defined narrowly and with care to avoid unnecessary interference with these freedoms.

Freedom is primordial at universities. This paper has shown that civility and respectful workplace policies take the authority to set standards of courtesy for granted, and appear to do so despite serious consequences for academic and expressive freedom. It has drawn on the Charter to demonstrate that expression cannot be regulated simply because it is taken or experienced as offensive. It has explained that the university context and its principle of academic freedom call for 
302

ACADEMIC FREEDOM IN CONFLICT

particular vigilance where institutional policies seek to deter or punish expressive activity content or manner/considered uncivil or disrespectful.

The analysis leads to the conclusion that, in the absence of more careful definitions, civility and respectful workplace policies violate academic and expressive freedom. Policies that include enforcement mechanisms should be abandoned in favour of alternative approaches that are collaborative rather than coercive in nature.

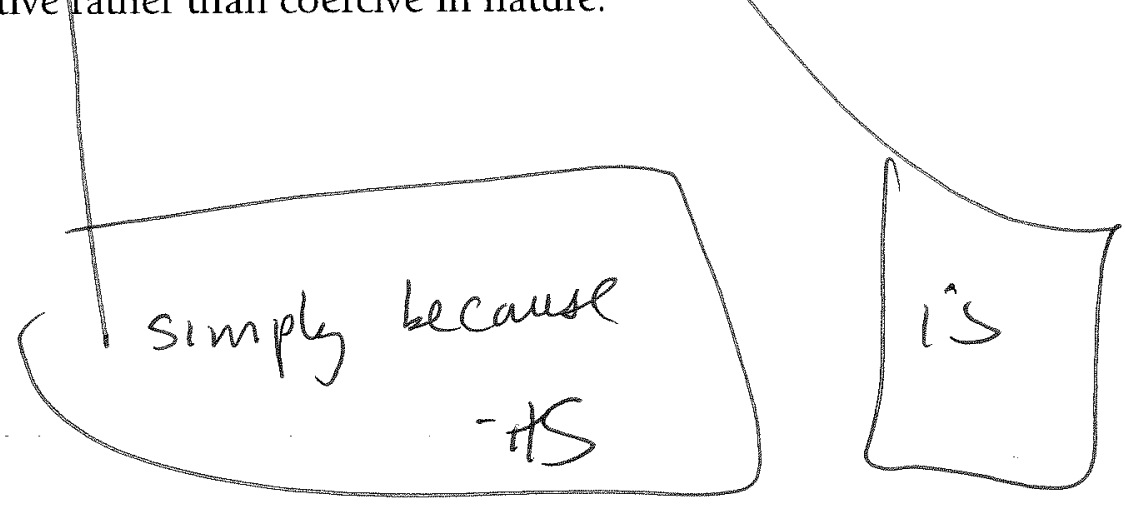




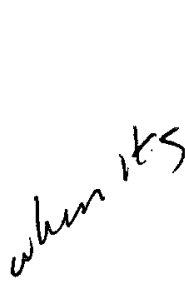

particular vigilance there institutional policies geek to deter or punish expressive activity content or mannef considered uncivil or disrespectful.

The analysis leads to the conclusion that, in the absence of more careful definitions, civility and respectful workplace policies violate academic and expressive freedom. Policies that include enforcement mechanisms should be abandoned in favour of alternative approaches that are collaborative rather than coercive in nature. 